\title{
Những giá trị nổi bật về quyền con người của Hiến pháp năm 1946 và sự kế thừa, phát triển trong Hiến pháp năm 2013
}

\author{
Vũ Công Giao*, Nguyễn Thuỳ Dương \\ Khoa Luật, Đại học Quốc gia Hà Nội, 144 Xuân Thủy, Cầu Giá́y, Hà Nội, Việt Nam \\ Nhận ngày 12 tháng 4 năm 2017 \\ Chỉnh sửa ngày 30 tháng 05 năm 2017; Chấp nhận đăng ngày 28 tháng 6 năm 2017
}

\begin{abstract}
Tóm tắt: Bài viết phân tích những quy định của Hiến pháp 1946 về quyền công dân và sự kế thừa, phát triển trong Hiến pháp năm 2013 của Việt Nam. Chế định nghĩa vụ và quyền lợi công dân trong Hiến pháp 1946 được xây dựng theo cách tiếp cận mở và rất khoa học, kết hợp hài hoà giữa những giá trị tiến bộ của văn minh phương Tây với những tư tưởng và điều kiện, hoàn cảnh đặc tưởng cơ bản về quyền con người trong Hiến pháp năm 1946 nhưng chưa triệt để, thể hiện ở việc chưa xác định việc bảo vệ, bảo đảm quyền con người như là một trong các nguyên tắc nền tảng của việc xây dựng Hiến pháp. Vì vậy, có thể khẳng định trong lịch sử lập hiến ở Việt Nam cho đến thời điểm hiện nay, đỉnh cao của tinh thần tôn trọng, đề cao quyền con người vẫn là bản Hiến pháp đầu tiên năm 1946.
\end{abstract}

Tù khóa: Quyền con người, quyền công dân, Hiến pháp 1946, Hiến pháp 2013, Việt Nam.

\section{Quyền công dân trong Hiến pháp năm 1946}

Hiến pháp năm 1946 được Quốc hội khóa I thông qua tại kỳ họp thứ 2 ngày 8/11/1946. Đây là bản Hiến pháp đầu tiên trong lịch sử của nước Việt Nam, có vai trò chính thức hóa chính quyền mới của nhân dân, khẳng định nền độc lập của dân tộc và chủ quyền của đất nước sau hơn nhiều năm bị thực dân Pháp đô hộ, ghi nhận và bảo vệ các quyền cơ bản của công dân.

Bản Hiến pháp gồm 7 Chương với 70 Điều, trong đó các quyền và nghĩa vụ của công dân được quy định tập trung tại Chương II với 18 Điểu (ngoài ra còn được thể hiện rải rác trong

\footnotetext{
*Tác giả liên hệ. ĐT.: 84-912105803.

Email: giaovc@vnu.edu.vn

https://doi.org/10.25073/2588-1167/vnuls.4081
}

một số điều khoản khác). Đây là lần đầu tiên trong lịch sử Việt Nam, các quyền của công dân được Hiến pháp - đạo luật cơ bản của quốc gia - ghi nhận và bảo đảm. Việc ghi nhận các quyền trong Hiến pháp năm 1946 có thể coi là sự kết nối từ việc đề cao nhân quyền trong Tuyên ngôn độc lập năm 1945, với đoạn mở đầu trích dẫn bản Tuyên ngôn độc lập của Hoa Kỳ năm 1776: "Tất cả mọi người đều sinh ra có quyền bình đẳng. Tạo hóa cho họ những quyền không ai có thể xâm phạm được; trong những quyền ấy, có quyền được sống, quyền tự do và quyền mưu cầu hạnh phúc" [1, 128].

Quyền công dân là vấn đề được đề cao một cách đặc biệt trong Hiến pháp 1946, hơn tất cả các Hiến pháp về sau của Việt Nam. Điều đó trước hết thể hiện ở việc chế định về quyền và nghĩa vụ của công dân trong Hiến pháp năm 
1946 được đặt ở Chương II, chỉ sau quy định về chính thể, và trước cả quy định về các cơ quan quyền lực nhà nước. Vị trí trang trọng này không được tiếp tục duy trì trong các Hiến pháp 1959, 1980, 1992, mà chỉ được tái lập trong Hiến pháp năm 2013. Tuy nhiên, quan trọng hơn, Lời nói đầu của Hiến pháp năm 1946 khẳng định, việc đảm bảo các quyền tư do dân chủ là một trong ba nguyên tắc làm nền tảng cho việc xây dựng bản Hiến pháp này (cùng với hai nguyên tắc khác là Đoàn kết toàn dân, không phân biệt giống nòi, gái trai, giai cấp, tôn giáo và Thực hiện chính quyền mạnh mẽ và sáng suốt của nhân dân). Các Hiến pháp về sau của nước ta $(1959,1980,1992,2013)$ đều không quy định nguyên tắc đó. Lời nói đầu của Hiến pháp 1959, 1980, 1992 chỉ quy định quyền và nghĩa vụ của công dân là một trong các nội dung được hiến định, trong khi Hiến pháp 2013 không đề cập cụ thể đến vấn đề này.

Các quyền lợi của công dân được ghi nhận và bảo vệ trong Chương II Hiến pháp năm 1946 trải rộng trên tất cả các lĩnh vực dân sự, chính trị, kinh tế, xã hội, văn hóa, bao gồm cả các quyền cá nhân và quyền của nhóm.Những quyền cá nhân bao gồm:quyền bình đẳng về chính trị, kinh tế, văn hoá và bình đẳng trước pháp luật (Điều 6, Điều 7, Điều 9); quyền được tham gia chính quyền và công cuộc kiến quốc (Điều 7); quyền tự do ngôn luận (Điều 10), quyền tự do xuất bản (Điều 10), quyền tự do tổ chức và hội họp (Điều 10 ), quyền tự do tín ngưỡng (Điều 10), quyền tự do cư trú, đi lại trong nước và ra nước ngoài (Điều 10); quyền không bị bắt bớ, giam cầm tuỳ tiện (Điều 11); quyền không bị xâm phạm trái pháp luật vào nhà ở và thư tín (Điều 11); quyền bầu cử và ứng cử (Điều 18); quyền bãi miễn đại biểu do mình bầu ra (Điều 20); quyền phúc quyết Hiến pháp và những việc quan hệ đến vận mệnh quốc gia (Điều 21); quyền tư hữu tài sản (Điều 12); quyền học tập (Điều 15). Bên cạnh các quy định đã nêu, quyền cá nhân còn được quy định tại một số điều khoản tại Chương VI (Cơ quan tư pháp) của Hiến pháp năm 1946, bao gồm: quyền được xét xử công khai, trừ những trường hợp đặc biệt (Điều 67); quyền của bị cáo tự bào chữa hoặc nhờ luật sư bào chữa (Điều 67); quyền không bị tra tấn, đánh đập, ngược đãi (Điều 68).

Trong số các quyền cá nhân được Hiến pháp năm 1946 ghi nhận, quyền tư hữu tài sản vẫn được ghi nhận trong Hiến pháp năm 1959 (sở hữu của người lao động riêng lẻ và sở hữu của tư sản dân tộc), sau đó được ghi nhận lại trong Hiến pháp năm 1992, và nhấn mạnh trong Hiến pháp năm 2013. Chỉ có Hiến pháp 1980 là không ghi nhận quyền sở hữu. Sự thay đổi trong việc hiến định quyền này xuất phát từ và phản ánh những thay đổi trong nhận thức về chế độ sở hữu và mô hình quản lý kinh tế cũng như sự thay đổi về các điều kiện chính trị, kinh tế - xã hội, môi trường quốc tế, xu hướng phát triển kinh tế - xã hội (từ thị trường tự do đến tập trung quan liêu bao cấp, rồi quay lại thị trường tự do [theo định hướng XHCN]) ở Việt Nam trong thời kỳ từ năm 1946 đến năm 2013. Mặc dù quy định rất ngắn gọn, song một số quyền trong Hiến pháp 1946 vẫn có nội hàm rộng hơn so với quy định trong các Hiến pháp về sau. Ví dụ, quyền bầu cử, ứng cử được bảo đảm theo nguyên tắc bỏ phiếu tự do - điều mà không được tái ghi nhận trong các Hiến pháp 1959, 1980, 1992 và cả Hiến pháp 2013.

Những quyền của nhóm bao gồm: quyền của quốc dân thiểu số được bình đẳng và được [nhà nước] ưu tiên giúp đỡ (Điều 8), được học bằng tiếng của dân tộc mình ở trường tiểu học (Điều 15), được dùng tiếng nói của mình trước Tòa án (Điều 66); quyền bình đẳng của phụ nữ với đàn ông (Điều 9); quyền của người già cả hoặc tàn tật được [nhà nước] giúp đỡ (Điều 14); quyền của trẻ em được giáo dưỡng (Điều 14), được học tiểu học miễ் phí và được [nhà nước] trợ giúp (với trẻ em nghèo) (Điều 15); quyền của các giới cần lao trí thức và chân tay [được bảo đảm] (Điều 13). Quyền của hầu hết các nhóm này sau đó tiếp tục được đề cập và cụ thể hoá trong các Hiến pháp 1959, 1980, 1992, 2013.

Từ những quy định trên, có thể thấy hệ thống các quyền công dân được ghi nhận trong Hiến pháp năm 1946 rất toàn diện, bao gồm tất cả các quyền cá nhân trên các lĩnh vực dân sự, chính trị, kinh tế, xã hội, văn hóa và và quyền 
của những nhóm xã hội dễ bị tổn thương chủ yếu. Theo nghĩa đó, mặc dù không đề cập đến khái niệm quyền con người, song về bản chất các quyền công dân trong Chương II của Hiến pháp năm 1946 cũng chính là các quyền con người mà sau đó được ghi nhận trong Tuyên ngôn toàn thế giới về nhân quyền (UDHR) năm 1948 và hai Công ước quốc tế về các quyền dân sự, chính trị (ICCPR) và Công ước về các quyền kinh tế, xã hội, văn hoá (ICESCR) năm 1966, ví dụ như quyền tự do biểu đạt (Điều 19 UDHR, Điều 19 ICCPR); quyền tự do hội họp, lập hội (Điều 20 UDHR, Điều 21, Điều 22 ICCPR); cấm tra tấn, đối xử tàn bạo, vô nhân đạo hoặc hạ nhục (Điều 5 UDHR, Điều 7 ICCPR); quyền được kết hôn và lập gia đình (Điều 16 UDHR, Điều 10 ICESCR);... Đặc biệt, Điều 16 Hiến pháp năm 1946 quy định: "Những người ngoại quốc tranh đấu cho dân chủ và tự do mà phải trốn tránh thì được trú ngụ trên đất Việt Nam". Đây chính là một quy định rõ ràng về quyền con người (quyền được tị nạn, quy định tại Điều 14 Tuyên ngôn toàn thế giới về nhân quyền năm 1948) trong Hiến pháp năm 1946, vì chủ thể của quyền trong Điều này không phải là công dân Việt Nam. Vì thế, có thể kêt luận rằng trong lĩnh vực nhân quyền, Hiến pháp 1946 có tính vuợt trước so với luật nhân quyền quốc tế. Sự vượt trước này chứng tỏ sự hiểu biết và tầm nhìn rất sâu rộng, tiến bộ về dân chủ, nhân quyền của các nhà lập hiến Việt Nam thời kỳ đó.

So sánh với các quyền con người cơ bản được ghi nhận trong luật nhân quyền quốc tế và các bản Hiến pháp trên thế giới [2, tr.26-57], có thể thấy khuôn khổ các quyền được hiến định trong Hiến pháp năm 1946 là khá phong phú, thuộc nhóm những Hiến pháp ghi nhận số lượng quyền cao, và đã bao hàm hầu hết những quyền con người cơ bản của luật nhân quyền quốc tế. Đặc biệt, cách thức quy định các quyền công dân trong Hiến pháp năm 1946 phản ánh triết lý về quyền tự nhiên của con người, xem các quyền con người là bẩm sinh, vốn có của mọi cá nhân. Điều này thể hiện rõ ở việc xác định việc bảo đảm quyền như là một nguyên tắc nền tảng để xây dựng Hiến pháp (Lời nói đầu) và trong cách quy định vị thế chủ thể quyền của người dân, như: "Tất cả công dân Việt Nam đều ngang quyền..."; "Tất cả công dân Việt Nam đều bình đẳng trước pháp luật...”; “Tư pháp chưa quyết định thì không được bắt bớ và giam cầm người công dân Việt Nam";... Những quy định này cho thấy Hiến pháp không quy định cho người dân các quyền và tự do đã nêu, mà thừa nhận đó là những giá trị tự nhiên mà nhà nước có trách nhiệm phải hiến định để bảo đảm thực hiện.

Cách thức hiến định các quyền trong Hiến pháp năm 1946 là sự tiếp thu tư tưởng tiến bộ về nhân quyền trong Tuyên ngôn Độc lập 1776 của Hoa Kỳ và Tuyên ngôn Nhân quyền và Dân quyền 1789 của cách mạng Pháp, đồng thời là sự tiếp nối tư tưởng của Chủ tịch Hồ Chí Minh về quyền con người trong Tuyên ngôn độc lập 1945. Triết lý này có ý nghĩa đặc biệt quan trọng, vì nó xác định rõ vị thế của nhà nước là chủ thể có nghĩa vụ thừa nhận, tôn trọng, bảo vệ, bảo đảm quyền con người chứ không phải là chủ thể "ban phát" các quyền con người cho người dân. Như vậy, mọi hành vi lợi dụng hay nhân danh việc thực thi quyền lực nhà nước để tuỳ tiện hạn chế, vi phạm các quyền của công dân đều không phù hợp với vị thế của nhà nước và cần phải bị ngăn chặn, xử lý. Đây là triết lý được cộng đồng quốc tế thừa nhận rộng rãi và được xem là nền tảng cho việc pháp điển hoá các quyền con người trong luật nhân quyền quốc tế sau này. Tuy nhiên, triết lý này đã không được coi trọng trong các Hiến pháp 1959, 1980, 1992, và chỉ được phục hồi trong Hiến pháp 2013. Như vậy, việc hiến định quyền theo triết lý về quyền tự nhiên trong Hiến pháp 1946 cũng thể hiện nhận thức có tính vượt trước so với luật nhân quyền quốc tế, và là một điểm tiến bộ vượt trội của bản Hiến pháp này so với các bản hiến pháp về sau của nước ta.

Trong Hiến pháp 1946, các quyền công dân được hiến định theo một cách thức rất ngắn gọn, trực tiếp, dễ hiểu, cho phép xác định rõ cả về chủ thể và nội dung chính, trong đó hầu hết các quy định nêu cả phạm vi/giới hạn của quyền. Cách quy định đó được kế thừa trong các Hiến pháp về sau của Việt Nam, nhưng độ 
hàm súc đều kém hơn so với Hiến pháp 1946. Đặc biệt, quy định về phạm vi, giới hạn của các quyền trong Hiến pháp 1946 rất hợp lý, không có gì mâu thuẫn với các quy định của luật nhân quyền quốc tế được ban hành những năm sau đó (xem bảng dưới đây). Những điều này cho thấy các nhà lập hiến thời kỳ đó có trình độ kỹ thuật lập hiến rất cao và nhận thức rất sâu sắc về bản chất của quyền con người.

\begin{tabular}{|c|c|c|c|}
\hline Điều & Tên quyền & Chủ thể của quyền & Phạm vi/giới hạn của quyền \\
\hline $\begin{array}{l}\text { Điều 6, } \\
\text { Điều } 7\end{array}$ & Quyền bình đẳng & Mọi công dân & $\begin{array}{l}\text { Các phương diện chính trị, kinh tế, } \\
\text { văn hoá và trước pháp luật }\end{array}$ \\
\hline Điều 7 & $\begin{array}{l}\text { Quyền tham gia chính quyền và } \\
\text { công cuộc kiển quốc }\end{array}$ & Mọi công dân & Tuỳ theo tài năng và đức hạnh \\
\hline Điều 8 & Quyền của quốc dân thiểu số & $\begin{array}{l}\text { Mọi quốc dân thiểu } \\
\text { số }\end{array}$ & $\begin{array}{l}\text { Bình đẳng về mọi quyền lợi, được } \\
\text { [nhà nước] giúp đờ trên mọi } \\
\text { phương diện đề chóng tiến kịp trình } \\
\text { độ chung }\end{array}$ \\
\hline Điều 9 & Quyền bình đẳng giới & Đàn bà và đàn ông & Bình đẳng về mọi phương diện \\
\hline Điều 11 & $\begin{array}{l}\text { Quyền được bảo vệ về nhà ở và } \\
\text { thư tín }\end{array}$ & Mọi công dân & $\begin{array}{l}\text { Chỉ những hành vi xâm phạm một } \\
\text { cách trái pháp luật }\end{array}$ \\
\hline Điều 14 & Quyền được nhà nước trợ giúp & $\begin{array}{l}\text { Những công dân già } \\
\text { cả hoặc tàn tật }\end{array}$ & Chỉ khi không làm được việc \\
\hline Điều 15 & $\begin{array}{l}\text { Quyền được học bằng tiếng của } \\
\text { dân tộc mình }\end{array}$ & $\begin{array}{l}\text { Mọi quốc dân thiểu } \\
\text { số }\end{array}$ & Ở các trường sơ học địa phương \\
\hline Điều 15 & Quyền của trẻ em & $\begin{array}{l}\text {-Được giáo dưỡng } \\
\text { - Được nhà nước trợ } \\
\text { giúp }\end{array}$ & $\begin{array}{l}\text {-Mọi trẻ em } \\
\text {-Chỉ học trò nghèo }\end{array}$ \\
\hline Điều 16 & Quyền tỵ nạn ở Việt Nam & Người nước ngoài & $\begin{array}{l}\text { Tranh đấu cho dân chủ và tự do mà } \\
\text { phải trốn tránh khi ở nước mình }\end{array}$ \\
\hline Điều 18 & Quyền bầu cử & Công dân Việt Nam & $\begin{array}{l}\text { Từ } 18 \text { tuổi, không bị mất trí và mất } \\
\text { công quyền }\end{array}$ \\
\hline Điều 18 & Quyền ứng cử & Công dân Việt Nam & $\begin{array}{l}\text { Từ } 21 \text { tuổi, có quyền bầu cử, biết } \\
\text { đọc, biết viết chữ quốc ngữ }\end{array}$ \\
\hline Điều 67 & Quyền được xét xử công khai & Bị cáo & $\begin{array}{l}\text { Trừ những trường hợp đặc biệt có } \\
\text { thể xét xử kín }\end{array}$ \\
\hline
\end{tabular}

Về mặt cấu trúc, Chương II của Hiến pháp năm 1946 được sắp xếp theo hướng quy định nghĩa vụ (gồm nghĩa vụ bảo vệ Tổ quốc, tôn trọng Hiến pháp, tuân theo pháp luật và nghĩa vụ đi lính) trước các quyền lợi. Việc đề cập đến nghĩa vụ trước quyền lợi của công dân làm cho cẩu trúc của chế định nhân quyền trong Hiến pháp 1946 trở lên rất đặc biệt, không theo cách thức của bất kỳ bản hiến pháp nào về sau của nước ta, cũng như khác lạ với hiến pháp của hầu hết các quốc gia trên thế giới. Điều này thể hiện rõ ràng ý định của các nhà lập hiến là đề cao nghĩa vụ của công dân. Sự sắp xếp như vậy mang tính chất tình thế, để phù hợp với hoàn cảnh đất nước khi ây đang trong tình thế "thù trong", "giặc ngoài", do đó việc bảo vệ Tổ quốc là nhiệm vụ quan trọng và cấp bách nhất, đòi hỏi tất cả công dân phải đặt nghĩa vụ với Tổ quốc lên trước các quyền lợi của cá nhân. Như vậy, việc đặt nghĩa vụ lên trước không làm giảm ý nghĩa và tầm quan trọng của vấn đề quyền công dân trong Hiến pháp 1946, ngược lại, việc này cho thấy tư duy của các nhà lập hiến thời kỳ đó rất thực tiễn, sáng tạo.

Cùng với việc hiến định các quyền con người, Hiến pháp năm 1946 còn xác lập được những nguyên tắc và phương thức tổ chức quyền lực chống lại sự lạm quyền của các cơ quan nhà nước, giúp bảo vệ các quyền tự do dân chủ của nhân dân. Điều này thể hiện trước 
hết ở việc các quyền con người được Hiến pháp ghi nhận và đảm bảo (xem Lời nói đầu của Hiến pháp), chứ không phải do "nhà nước". Hiến pháp, do Quốc hội lập hiến - đại diện cho quyền lực của nhân dân - ban hành. Mọi sự sửa đổi, ngoài các thủ tục, cần phải được đưa ra để toàn dân phúc quyết (Điều 70). Như vậy, có thể thấy Hiến pháp có vị thế cao hơn nhà nước. Nhà nước (hay Nghị viện nhân dân) không thể tự mình sửa đổi Hiến pháp. Do đó, các quyền được Hiến pháp ghi nhận sẽ có giá trị bảo đảm cao hơn, không lo ngại sẽ bị nhà nước hạn chế một cách tùy tiện.

Từ góc độ quản trị quốc gia, thiết kế của Hiến pháp năm 1946 giúp kiểm soát quyền lực nhà nước tốt hơn so với các Hiến pháp về sau của Việt Nam, thông qua cơ chế phân quyền, cân bằng, đối trọng và kiểm soát lẫn nhau khá rõ ràng giữa các nhánh quyền lực lập pháp, hành pháp, tư pháp. Ví dụ, về quyền lực của nhánh lập pháp, Hiến pháp năm 1946 quy định quyền của Ban thường vụ Nghị viện nhân dân được biểu quyết những dự án sắc luật của Chính phủ, kiểm soát và phê bình Chính phủ; quyền ưng chuẩn hoặc phế bỏ sắc luật của Nghị viện nhân dân (Điều 36); Nghị viện nhân dân có quyền biểu quyết vấn đề tín nhiệm đối với Nội các, và có thể dẫn đến việc Nội các phải từ chức nếu bị biểu quyết bất tín nhiệm (Điều 54); Nghị viên không bị truy tố vì lời nói hay lời biểu quyết trong Nghị viện (Điều 40). Về phía hành pháp, Hiến pháp năm 1946 quy định Chủ tịch nước (đứng đầu nhánh hành pháp) không phải chịu trách nhiệm nào trước Nghị viện nhân dân, trừ khi phạm tội phản quốc (Điều 50); Chủ tịch nước có quyền yêu cầu Nghị viện nhân dân thảo luận lại dự án luật đã được Nghị viện biểu quyết (Điều 31). Về phía nhánh tư pháp, theo Hiến pháp 1946, cơ quan tư pháp được tổ chức theo cấp xét xử (Điều 63), có quyền độc lập trong khi xét xử, chỉ tuân theo pháp luật, các cơ quan khác không được can thiệp (Điều 69). Rất nhiều quy định đã nêu không được ghi nhận lại trong các Hiến pháp về sau của Việt Nam. Những quy định này là cơ sở pháp lý để kiểm soát, hạn chế sự lạm quyền của các cơ quan nhà nước, đồng thời ở tầm vĩ mô giúp hạn chế những vi phạm nhân quyền, bảo đảm thực thi các quyền cồng dân được hiến định trong Hiến pháp năm 1946.

\section{Sự kế thừa, phát triển trong Hiến pháp năm 2013}

Hiến pháp năm 2013 được Quốc hội khóa XIII thông qua ngày 28/11/2013, là bản Hiến pháp thứ năm trong lịch sử lập hiến Việt Nam (không tính đến hai bản Hiến pháp năm 1956 và 1967 được ban hành bởi chính quyền Miền Nam trong thời gian chiến tranh chống Mỹ). Xét tổng quát, so với các bản Hiến pháp trước, Hiến pháp năm 2013 không phải là bước ngoặt, ghi dâu ân thể chế (như Hiến pháp năm 1946, hay 1992), mà chỉ là sự mở rộng, đào sâu những định hướng cải tổ đã được đề cập trong bản Hiến pháp năm 1992 trước đó. Tuy nhiên, điểm đặc biệt là Hiến pháp 2013 cho thấy sự chuyển động quay trở lại của những nhận thức và chính sách đặc biệt quan trọng về nhân quyền mà được xác lập trong Hiến pháp 1946 nhưng đã bị lãng quên, xa rời trong các bản Hiến pháp 1959,1980 và 1992 của Việt Nam (cho dù Hiến pháp năm 1992 đã có nhắc đến thuật ngữ "quyền con người" tại Điều 50 , vấn đề quyền con người vẫn chưa được quy định rõ ràng trong bản Hiến pháp này).

Một số điểm cho thấy Hiến pháp năm 2013 kế thừa tư tưởng và giá trị nhân quyền của Hiến pháp năm 1946 đó là:

- Trong Hiến pháp năm 2013, chế định "Quyền con người, quyền và nghĩa vụ của công dân” được đặt ở vị trí thứ hai (giống Hiến pháp năm 1946). Bên cạnh đó, Hiến pháp 2013 nêu rõ Nhà nước có nghĩa vụ công nhận, tôn trọng, bảo vệ, bảo đảm các quyền con người, quyền công dân (Điều 3 và 14). Như vậy, so với các Hiến pháp 1959,1980,1992, quan điểm và cách hiến định quyền trong Hiến pháp năm 2013 đã được thay đổi hẳn từ mô thức nhà nước "quyết định", "trao" quyền cho người dân sang mô thức các quyền con người là tự nhiên, vốn có, nhà nước phải ghi nhận, bảo vệ và bảo đảm thực hiện - tức là giống cách thức xác lập 
quyền trong Hiến pháp năm 1946. Sự thay đổi này có ý nghĩa quan trọng nhất, vì tạo ra tác động tổng thể, ở tầm vĩ mô với việc tôn trọng, bảo vệ và bảo đảm nhân quyền. Sự thay đổi này cũng cho thấy về mặt nhận thức các nhà lập hiến Việt Nam đã quay trở về tư tưởng về quyền tự nhiên trong Hiến pháp năm 1946, sau một thời kỳ dài bị ảnh hưởng bởi tư tưởng về quyền pháp lý.

- Tương tự như Hiến pháp năm 1946, thành phần các quyền hiến định trong Hiến pháp năm 2013 cũng bao gồm các quyền dân sự, chính trị, kinh tế, xã hội, văn hóa, đồng thời vẫn ghi nhận quyền tỵ nạn của người nước ngoài và quyền của các nhóm dễ bị tổn thương như phụ nữ, trẻ em, người khuyết tật, dân tộc thiểu số...

Ngoài những điểm kế thừa Hiến pháp năm 1946 đã nêu trên, Hiến pháp năm 2013 còn có những quy định mà có thể coi là sự phát triển so với Hiến pháp năm 1946, tiêu biểu như sau:

- So với Hiến pháp năm 1946, Hiến pháp năm 2013 sử dụng cả hai thuật ngữ "quyền con người" và "quyền công dân" để chỉ các quyền/tự do được hiến định tại Chương II. Điều này cho phép ghi nhận và bảo đảm các quyền con người một cách cu thể và chính xác hơn, phù hợp với các tiêu chuẩn của luật quốc tế.

- Ngoài nghĩa vụ bảo đảm như trong Hiến pháp năm 1946, Hiến pháp năm 2013 còn ghi nhận cả nghĩa vụ "tôn trọng" và "bảo vệ" các quyền con người. Điều này phù hợp với các nghĩa vụ của quốc gia theo luật nhân quyền quốc tế và giúp tăng cường trách nhiệm của nhà nước trong lĩnh vực này.

- Hiến pháp năm 2013 lần đầu tiên quy định "nguyên tắc giới hạn quyền" (Điều 14(2)) - một nguyên tắc phù hợp với luật nhân quyền quốc tế. Mặc dù quy định này vẫn còn hạn chế là chưa xác định những quyền tuyệt đối không thể bị giới hạn hay tước bỏ, dẫn đến nguy cơ những quyền này có thể bị vi phạm nhân danh Điều 14(2); song quy định nguyên tắc giới hạn quyền cũng có tác dụng hạn chế sự tuỳ tiện của các cơ quan nhà nước trong các vấn đề nhân quyền.

- So với Hiến pháp năm 1946, Hiến pháp năm 2013 đã ghi nhận nhiều quyền mới, bao gồm: quyền của công dân không thể bị trục xuất, giao nộp cho nhà nước khác; quyền sống; quyền bất khả xâm phạm về thân thể; quyền hiến mô, bộ phận cơ thể người và hiến xác; quyền riêng tư; quyền bảo vệ danh dự, uy tín; quyền khiếu nại, tố cáo; quyền có nơi ở hợp pháp; quyền tự do báo chí, tiếp cận thông tin, biểu tình; quyền biểu quyết trong trưng cầu ý dân; quyền được xét xử kịp thời, công bằng; quyền không bị kết án hai lần vì một tội phạm; quyền được bồi thường và phục hồi danh dự khi bị oan sai trong tố tụng; quyền tự do kinh doanh; quyền được bảo đảm an sinh xã hội; quyền về việc làm; quyền kết hôn, ly hôn; quyền được bảo vệ, chăm sóc sức khỏe; quyền xác định dân tộc của mình, sử dụng ngôn ngữ mẹ đẻ, lựa chọn ngôn ngữ giao tiếp; quyền được sống trong môi trường trong lành;... Những sự sửa đổi, bổ sung đó làm cho chế định này của Hiến pháp năm 2013 phù hợp hơn với nội dung của các điều ước nhân quyền quốc tế mà Việt Nam là thành viên.

- Hiến pháp năm 2013 quy định một nhiệm vụ quan trọng cho Tòa án, đó là "bảo vệ công lý, bảo vệ quyền con người, quyền công dân" (Điều 102(2)) - quy định cho thấy ý tưởng của các nhà lập hiến muốn thúc đẩy quá trình cải tổ hệ thống tòa án, từ vị trí là công cụ tư pháp bảo vệ chế độ sang vị trí là thiết chế bảo vệ công lý trong nhà nước pháp quyền. Viện kiểm sát là một thiết chế hoàn toàn mới nếu so với Hiến pháp năm 1946. Cơ quan này có chức năng thực hành quyền công tố và kiểm soát hoạt động tư pháp; với nhiệm vụ "bảo vệ pháp luật, bảo vệ quyền con người, quyền công dân", "bảo vệ lợi ích của Nhà nước, quyền và lợi ích hợp pháp của tổ chức, cá nhân", "góp phần bảo đảm pháp luật được chấp hành nghiêm chỉnh và thống nhất" (Điều 107(3)).

- Ở góc độ rộng hơn, Hiến pháp năm 2013 cho thấy sự tái khẳng định và phát triển tư tưởng về chủ quyền của nhân dân với Hiến pháp (đã được nêu trong Hiến pháp năm 1946) thông qua việc xác định: “....Nhân dân Việt Nam xây dựng, thi hành và bảo vệ Hiến pháp này..." (Lời nói đầu). Lần đầu tiên trong lịch sử lập hiến, cụm từ "Nhân dân" đều được viết hoa 
- điều được lý giải là để "thể hiện sự tôn trọng và đề cao vai trò của Nhân dân với tư cách là chủ thể duy nhất của toàn bộ quyền lực nhà nước" [3]. Hiến pháp cũng đã làm rõ và mở rộng hơn các phương thức thực hiện các quyền dân chủ của nhân dân, đặc biệt là tạo cơ sở để thúc đẩy các hình thức dân chủ trực tiếp (như trưng cầu ý dân), ${ }^{1}$ bằng việc quy định: "Nhân dân thực hiện quyền lực nhà nước bằng dân chủ trực tiểp, bằng dân chủ đại diện thông qua Quốc hội, Hội đồng nhân dân và thông qua các cơ quan khác của Nhà nước" (Điều 6). Một thiết chế hiến định hoàn toàn mới - Hội đồng bầu cử quốc gia - đã được Hiến pháp năm 2013 quy định, nhằm tăng cường, hoàn thiện các hình thức dân chủ trực tiếp của nhân dân (bầu cử). Đây là những yếu tố thuận lợi với việc bảo vệ và thúc đẩy nhân quyền.

\section{Kết luận}

Hiến pháp năm 2013 đã thể hiện sự kế thừa và phát triển những tư tưởng và nguyên tắc cơ bản về quyền con người, quyền công dân trong Hiến pháp năm 1946. Những kế thừa, phát triển đó tạo lập cách tiếp cận gắn bó chặt chẽ hơn với nhận thức chung của nhân loại và các tiêu chuẩn của luật nhân quyền quốc tế. Theo cách đó, Hiến pháp năm 2013 đã đánh dấu một bước tiến lớn trong vấn đề nhân quyền so với các bản Hiến pháp năm 1959, 1980, và 1992. Nó cho thấy nỗ lực của các nhà lập hiến trong việc hoàn thiện khuôn khổ hiến định để bảo đảm tốt hơn các quyền con người, quyền công dân ở Việt Nam trong thời gian tới.

\footnotetext{
${ }^{1}$ Quyền biểu quyết khi nhà nước tổ chức trưng cầu ý dân trong Hiến pháp năm 2013 về cơ bản cũng giống như quyền phúc quyết Hiến pháp và những việc quan hệ đến vận mệnh quốc gia trong Hiến pháp năm 1946. Khác biệt duy nhất đó là, theo Hiến pháp năm 1946, bất cứ sửa đổi Hiến pháp nào cũng sẽ đều được đưa ra phúc quyết. Còn theo Hiến pháp năm 2013, nếu nhà nước không tổ chức trưng cầu ý dân thì nhân dân sẽ không có quyền biểu quyết về các sửa đổi của Hiến pháp (tại Điều 120(4) quy định: "Việc trưng cầu ý dân về Hiến pháp do Quốc hội quyết định).
}

Mặc dù vậy, về mặt học thuật, có thể thấy so với Hiến pháp 1946, sự kế thừa của Hiến pháp 2013 vẫn chưa triệt để, thể hiện ở việc Hiến pháp 2013 vẫn chưa xác định việc bảo vệ, bảo đảm quyền con người, quyền công dân như là một trong các nguyên tắc nền tảng của việc xây dựng Hiến pháp, và trong nhiều quy định của chương 2 , vẫn có thể thấy sự "ngập ngừng" của các nhà lập hiến trong việc xử lý mối quan hệ giữa nghĩa vụ/trách nhiệm và sự kiểm soát của nhà nước trong vấn đề nhân quyền. Những sự phát triển của Hiến pháp 2013 chủ yếu là cập nhật những quyền con người và một số quy định có liên quan được ghi nhận trong luật nhân quyền quốc tế - ngành luật mà ở thời điểm 1946 vẫn chưa hình thành. Những phát triển đó mặc dù giúp củng cố và mở rộng những bảo đảm với các quyền con người, song vẫn chưa thể tạo ra được một môi trường và thiết chế thuận lợi cho việc tôn trọng, bảo vệ và bảo đảm quyền con người như Hiến pháp 1946.

Do đó, có thể khẳng định rằng, xét tổng quát, trong lịch sử lập hiến ở Việt Nam cho đến thời điểm hiện nay, đỉnh cao của tinh thần tôn trọng, đề cao nhân quyền vẫn là bản Hiến pháp đầu tiên năm 1946. Trong bản Hiến pháp này, vấn đề quyền con người, quyền công dân được đặc biệt đề cao, theo những cách thức và mức độ hơn hẳn so với tất cả các bản Hiến pháp về sau của Việt Nam. Chế định nhân quyền trong Hiến pháp 1946 được xây dựng theo cách tiếp cận cởi mở, tiến bộ, cập nhật với tư tưởng chung của nhân loại, nhưng khoa học, chặt chẽ và mang tính thực tế cao. Từ cách tiếp cận, nội dung cho đến ngôn ngữ sử dụng trong việc hiến định các quyền công dân trong Hiến pháp năm 1946 cho thấy có sự kết hợp hài hoà giữa những giá trị tiến bộ của văn minh phương Tây với những tư tưởng và điều kiện, hoàn cảnh đặc thù của dân tộc Việt Nam ở thời kỳ đó. Những điều này góp phần khẳng định giá trị và tính độc đáo của Hiến pháp năm 1946 trong lịch sử lập hiến Việt Nam. Cách tiếp cận, kỹ thuật và nội dung hiến định về quyền trong Hiến pháp năm 1946 cho đến nay vẫn là các tiêu chí tham khảo quan 
trọng cho việc sửa đổi, bổ sung và thực hiện các quyền hiến định ở nước ta./.

\section{Tài liệu tham khảo}

[1] Nguyễn Đăng Dung (2009), "Những giá trị của Hiến pháp 1946 và mô hình tổ chức với việc ứng dụng nó cho công cuộc cải cách bộ máy nhà nước hiện nay", trong cuốn: Phát huy những giá trị lịch sử, chính trị, pháp lý của Hiến pháp 1946 trong sự nghiệp đổi mới hiện nay, Nxb. Chính trị quốc gia, Hà Nội, tr.128.

[2] Vũ Công Giao (2012), “Quyền con người, quyền công dân trong Hiến pháp trên thế giới và Hiến pháp Việt Nam: Sơ bộ phân tích so sánh", trong cuốn: Sửa đổi, bổ sung Hiến pháp 1992: Những vấn đề lý luận và thực tiễn (Tập II, Nxb. Hồng Đức, Hà Nội), tr.26-57.

[3] Phan Trung Lý, "Hiến pháp nước Cộng hòa xã hội chủ nghĩa Việt Nam - Hiến pháp dân chủ, pháp quyền và phát triển", (Bài phát biểu tại Hội nghị giới thiệu nội dung Hiến pháp nước Cộng hòa xã hội chủ nghĩa Việt Nam tại trường Đại học Luật Tp. Hồ Chí Minh, ngày 18/12/2013).

\title{
Outstanding Values of Human Rights in the 1946 Constitution and Their Succession and Development in the 2013 Constitution
}

\author{
Vu Cong Giao, Nguyen Thuy Duong \\ VNU School of Law, 144 Xuan Thuy, Cau Giay, Hanoi, Vietnam
}

\begin{abstract}
This paper analyzes the provisions on citizen's rights stipulated in the 1946 Constitution as well as the inheritance and the upgrading of these provisions in Vietnam Constitution 2013. The chapter on citizen's rights and duties in the 1946 Constitution has been developed with an open and scientific approach, in which the Western progressive values and Vietnamese traditions and context have been both equally considered. The authors demonstrate that the 2013 Constitution has inherited and upgraded the provisions on human rights in the 1946 Constitution, but has not stated that human rights protection and guarantee are fundamental principles in the building of the Constitution. As such, according to the authors, in the history of constitutional making of Vietnam, the 1946 Constitution is still the best in terms of respecting and upholding human rights.
\end{abstract}

Keywords: Human rights, citizen rights, the 1946 Constitution, the 2013 Constitution, Vietnam 